\title{
A Keynesian Endogenous Growth Theory with a Rigorous Microeconomic Foundation
}

\author{
Masayuki Otaki \\ Institute of Social Science, University of Tokyo, Tokyo, Japan \\ Email: ohtaki@iss.u-tokyo.ac.jp
}

Received June 2, 2012; revised July 2, 2012; accepted July 31, 2012

\begin{abstract}
Extending the effective demand theory developed by Otaki [1,2], we construct a demand-driven endogenous growth theory with a rigorous microeconomic foundation. An accelerator-principle investment function is derived by the intertemporal maximization behavior of monopolistic competitive employers. Under this investment function, an economy endogenously begins to expand even if the stability condition for goods markets is satisfied. Three factors determine the equilibrium growth rate: the degree of monopoly (the inverse of the price elasticity of each good) $\eta^{-1}$, the marginal propensity to saving $s$, and the Mashallian $k$ that can be manipulated by the government and is denoted by $\kappa$. The higher values of $\eta^{-1}$ and $s$, and the lower value of $\kappa$, the more rapidly the economy expands.
\end{abstract}

Keywords: Microeconomic Foundation for the Accelerator-Principle Investment Function; Progress of Labor Productivity; Demand-Driven Endogenous Growth; Self-Fulfilling Prophecy

\section{Introduction}

It is important to establish the dynamic microeconomic foundation of the Keynesian endogenous growth theory once we admit that some idle resources, such as labor, possibly exist even when an economy is expanding. On the basis of the standard two-period OLG model with money developed by Lucas [3] and Otaki [1,2], we construct a monetary growth model possessing such a feature.

Harrod [4] is the seminal work in this field. However, his investment function, which plays a crucial role in his theory, is not compatible with the intertemporal maximization behavior of the firm.

This paper defines the equipment investment as the cost of improving labor productivity. This is necessary for accomplishing more efficient and lower cost production to accumulate various intangible know-hows besides increasing in capital. Such costs constitute our notion of equipment investment.

Under the assumption of monopolistic competition in goods markets, real GDP becomes a shift parameter for each small firm. If every firm expects future macroeconomic expansion, the optimal production increases, and thus, the benefit from cost reduction also increases. Accordingly, whenever higher future economic growth is rationally anticipated, current equipment investment is accelerated and the expectations become self-fulfilling. This is our microeconomic foundation for the accelera- tor-principle investment function proposed by Hicks [5].

There are three crucial factors that determine the equilibrium growth rate: the degree of monopoly (the inverse of the relative price elasticity of each good) $\eta^{-1}$, the marginal propensity to saving $s$, and the Marshallian $k$, which is denoted by $\kappa$.

When employers can obtain more marginal monopoly profits $\eta^{-1}$, they find the business environment favorable, and thus, increase their equipment investment. Accordingly, a higher value of $\eta^{-1}$ increases the equilibrium growth rate. Second, high marginal propensity to saving $s$ implies that the funds are sufficient for equipment investment. This also increases the growth rate. Third, when the nominal money stock per nominal GDP (i.e., the Marshallian $k$ ) $\kappa$ takes a higher value, more resources are allotted to the older generation's consumption. As a result, fewer funds are available for investment, thus, dampening economic growth.

The remainder of the paper is organized as follows. In Section 2, we construct the model and solve the equilibrium growth rate, and explore the welfare economic implications. Section 3 contains our concluding remarks.

\section{Model}

\subsection{Structure of the Model}

We use essentially the same model as that of Otaki [1] except for the equipment investment decision. In every 
period, individuals are born in the dense of $[0,1] \times[0,1]$. This implies that there is no population growth. There are differentiated goods $z$ in the dense of $[0,1]$. Each good is monopolistically produced by a single employer $z$. Fiat money is the only store of value.

Each individual has the identical utility function $U$ :

$$
\begin{aligned}
U & \equiv c_{1 t}^{1-s} c_{2 t+1}^{s}-\delta_{t} \alpha, \\
c_{i, t+j} & \equiv\left[\int_{0}^{1}\left[c_{i t+j}(z)\right]^{1-\eta^{-1}} \mathrm{dz}\right]^{11-\eta^{-1}}, 0<s<1,
\end{aligned}
$$

where $c_{i t+j}(z)$ is the consumption of $\operatorname{good} z$ during period $t+j$ at the ith stage of the life. $\alpha$ denotes the disutility of labor. $\delta$ is a definition function that is one when employed and zero when unemployed.

Each employer faces the production function $y^{s}(z)$ :

$$
y_{t}^{s}(z)=\gamma_{t-1}(z) l_{t}(z), \quad \gamma_{-1}(z)=\bar{\gamma}, \forall z,
$$

where $\gamma_{t-1}(z)$ is the current labor productivity accumulated by equipment investment. $l_{t}(z)$ denotes the employment level. The real investment cost function $I_{t}(z)$, which is deflated by the price index $P_{t}$, is defined as

$$
I_{t}(z)=\sigma\left[\gamma_{t}(z)-\gamma_{t-1}(z)\right], P_{t} \equiv\left[\int_{0}^{1}\left[p_{t}(z)\right]^{1-\eta} \mathrm{d} z\right]^{1-\eta}
$$

where $\sigma$ denotes the marginal cost for investment.

\subsection{Maximization Problem of Economic Agents}

\subsubsection{Individuals}

Since the utility function is (1), we can easily induce the demand function for $\operatorname{good} z, D_{t}(z)$ and the saving function $S$ as

$$
\begin{gathered}
D_{t}(z)=\left[\frac{p_{t}(z)}{P_{t}}\right]^{-\eta} y_{t}^{d}, \\
S\left(y_{t}\right)=s y_{t},
\end{gathered}
$$

where $y_{t}^{d}$ is the real aggregate effective demand and $y_{t}^{s}$ is the real national income.

Since the expenditure function is of the Cobb-Douglas form on prices, we can easily derive the nominal reservation wage $W_{t}^{R}$ as

$$
W_{t}^{R}=\alpha A P_{t}^{1-s} P_{t+1}^{s}, \quad A \equiv s^{s}(1-s)^{1-s} .
$$

In what follows, we assume that the equilibrium is interior in the sense that some individuals are always unemployed. Hence, the equilibrium nominal wage is equal to the nominal reservation wage $W^{R}$.

\subsubsection{Employers}

Every employer consists of a dynasty. Employers con- sider not only their own interests but also their descendants. The optimal behavior of an employer is assumed to be

$$
\begin{gathered}
\max _{\gamma_{t}(z), p_{t}(z)}\left[\left[\frac{p_{t}(z)}{P_{t}}-\frac{W_{t}^{R}}{P_{t} \gamma_{t-1}(z)}\right] D_{t}(z)-I_{t}(z)\right. \\
\left.-\tau_{t} \frac{P_{t+1}}{P_{t}}\left[\frac{W_{t+1}^{R}}{P_{t+1} \gamma_{t}(z)} D_{t+1}(z)\right]\right] .
\end{gathered}
$$

The first term of (7) represents the benefit of the current employer. The second term corresponds to the net benefit of their descendant (The labor-productivity improvement investment causes more efficient production (i.e., cost reduction).)

Although the inflation rate is the discount rate concerning future cost reduction, for simplicity, we assume that the gain from the inflation is entirely canceled by the corporate tax levied on the net benefit from the cost reduction. We denote the rate as $\tau_{t}$. That is, we assume that

$$
\tau_{t}=\frac{P_{t}}{P_{t+1}} .
$$

It is also assumed that future wages are actually paid by the employer who will assume control of the business in the next period ${ }^{1}$.

The solutions of (7) are

$$
\begin{gathered}
p_{t}^{*}(z)=\frac{W_{t}^{R}}{\left[1-\eta^{-1}\right] \gamma_{t-1}}, \\
I_{t}^{*}(z)=\left[1-\eta^{-1}\right]\left[y_{t+1}^{d}-y_{t}^{d}\right] .
\end{gathered}
$$

Equation (9) is our investment function that gives a microeconomic foundation for the acceleration principle. Furthermore, from (3) and (9), we must note that the aggregate employment $l_{t}$ is obtained as

$$
l_{t}=\frac{y_{t}^{d}}{\gamma_{t-1}}=\frac{\sigma}{1-\eta^{-1}}<1 \text {. }
$$

Thus, the unemployment rate is independent of the equilibrium growth rate whenever effective demand grows at the same velocity as does labor productivity improvement ${ }^{2}$.

\subsubsection{Government}

The government levies a tax that is proportional to the net additional cash flow of the firm. The gross tax rate is

${ }^{1}$ From the envelop theorem, it is clear that the maximization problem (7) is invariant even if future total sales $p_{t+1} D_{t+1}(z)$ is introduced to the objective function.

${ }^{2}$ Note that the unemployment level temporally diverges from (10) when an unexpected shock, such as monetary expansion, occurs in the economy. 


$$
\tau_{t}=\frac{P_{t}}{P_{t+1}}
$$

This tax is entirely and equally transferred to individuals regardless of whether they are employed. Consequently, the earned income that consists of wages and profits is entirely distributed to individuals.

Under this set-up, the only government revenue is the seigniorage. We assume that the monetary-fiscal policy of the government keeps the Marshallian $k$ constant, and that accrued seigniorage is entirely spent on wasteful objects and bears no social utility. That is,

$$
M_{t+1}=\left(1+g^{*}\right) \pi_{t}^{*} M_{t},
$$

where $M_{t+j}$ denotes the nominal money stock. $g^{*}$ is the equilibrium growth rate for which we solve. $\pi_{t}^{*}$ is the equilibrium gross inflation rate that is obtained from (6) and (8). That is,

$$
P_{t}^{*}=\frac{\alpha A\left[P_{t}^{*}\right]^{1-s}\left[P_{t+1}^{*}\right]^{s}}{\left[1-\eta^{-1}\right] \gamma_{t-1}} \Rightarrow \pi_{t}^{*}=\left[\frac{\left[1-\eta^{-1}\right] \gamma_{t-1}}{\alpha A}\right]^{\frac{1}{s}}
$$

Thus, inflation is accelerated by the evolution of labor productivity because the heightened labor productivity incessantly raises nominal wages. In turn, it implies that if the progress of labor productivity, which corresponds to the TFP in our model, stagnates and the growth rate slows, disinflation becomes prominent. This result is consistent not only with the empirical research on the Japanese economy by Hayashi and Prescott [6] but also with the downward-sloping long-run Phillips curve.

\subsection{Market Equilibrium}

Since we assume that the labor market is located at interior equilibrium, it is sufficient to analyze the equilibrium condition for the aggregate goods market. This condition is obtained by combining (5), (9), and (11):

$$
s y_{t}^{*}=\left[1-\eta^{-1}\right]\left[y_{t+1}^{*}-y_{t}^{*}\right]+\frac{M_{t}}{P_{t}} \Rightarrow s=\left[1-\eta^{-1}\right] g^{*}+\kappa \text {. }
$$

Thus, we obtain the equilibrium growth rate as

$$
g^{*}=\frac{s-\kappa}{1-\eta^{-1}} \equiv \sum_{j=0}^{+\infty} \eta^{-j}[s-\kappa] .
$$

Equations (13) and (14) have interesting economic implications. First, economic growth begins endogenously via the increase in equipment investment. The initial investment is caused by the rational animal spirits (Keynes [7], Ch. 12): the employers believe in the future expansion of the economy.

\footnotetext{
${ }^{3}$ Note that the employers rationally confirm that future effective demand proportionately increases with the progress of labor productivity.
}

If employers assume that the economy will forever stagnate, the equipment investment will become zero, and so will the economic growth rate. In such a case, as proved by Otaki [1], the traditional Hicks-Samuelson's $45^{\circ}$ analysis is valid. Hence, we must note that the mechanism of endogenous growth never depends on the instability of the goods-market equilibrium.

Second, the equilibrium growth rate $g^{*}$ is an increaseing function of $\eta^{-1}$ and $s$, and is also a decreasing function of $\kappa \cdot s-\kappa$ denotes the surplus of the economy normalized by the current real GDP. Accordingly, the economy has abundant funds for the economic growth, thereby increasing the growth rate. Accordingly, the expansionary monetary policy under the credibility of money (Otaki [8]) can stimulate the economy in the short run, but shortens the loanable funds surplus and lowers the growth rate in the long run.

Finally, the degree of monopoly $\eta^{-1}$ enhances economic growth since a higher $\eta^{-1}$ implies an improvement in the income distribution to profits and stimulates equipment investment. It is also worth noting that this effect is cumulative. That is, at the first stage, future real income grows by $s-\kappa$ per cent ${ }^{3}$. In the next stage, $s-\kappa$ bears the additional monopoly profit that amounts to $\eta^{-1}[s-m]$ because of the rightward shift of each good demand curve; thus, each firm expands its supply in response to the increment of the demand. Similarly, this income again bears income of $\eta^{-1}\left[\eta^{-1}[s-\kappa]\right]$. Such a cumulative process continues infinitely and converges to $\frac{s-\kappa}{1-\eta^{-1}}$.

\subsection{Welfare Implication}

Since, mainly for simplicity, we assume that the equilibrium nominal wage equals the nominal reservation wage, there is no welfare gain from the increase in employment. Accordingly, the source of welfare gain is confined to the real net cash flow $N C F_{t}^{*}$ :

$$
N C F_{t}^{*}=\left[\eta^{-1}-[s-\kappa]\right] y_{t}^{*} .
$$

The indirect utility function $I U$ is Cobb-Douglas:

$$
I U \propto \frac{N C F_{t}^{*}}{\left[\pi^{*}\right]^{s}}
$$

Substituting (10), (12) and (15) into the above equation, we obtain

$$
\begin{aligned}
& I U \propto \frac{\left[\eta^{-1}-[s-\kappa]\right] y_{t}^{*}}{[\alpha A]^{-1}\left[1-\eta^{-1}\right] \gamma_{t-1}^{*}} \\
= & \frac{\left[\eta^{-1}-[s-\kappa]\right]}{[\alpha A]^{-1}\left[1-\eta^{-1}\right]} l_{t}^{*}=\alpha A \sigma\left[\eta^{-1}-[s-\kappa]\right] .
\end{aligned}
$$


Thus, the economic growth never provides any additional benefits as long as economy suffers from an unemployment problem. The fruits of economic growth are entirely consumed by the acceleration of inflation.

Since $I U$ is an increasing function of $\kappa$, the most urgent problem in a national economy is to reduce the number of unemployed individuals as Otaki [2] proves, even if the equilibrium growth rate becomes zero. Economic growth is the second priority in the economy as a whole.

\section{Concluding Remarks}

We succeeded in constructing a Keynesian endogenous growth model based on neoclassical microeconomics that is as faithful as possible. Results obtained are as follows.

First, the equipment investment is the driving force of economic growth. Second, a higher degree of monopoly $\eta^{-1}$ (product differentiation) stimulates economic growth because it bears more profits and thus invokes the cost reduction investment. A high ratio of surplus funds $s-\kappa$ also contributes to the economic expansion since it makes it easer for employers to invest many resources for the equipment investment.

Third, although the economy grows autonomously, as long as there is a serious unemployment problem, economic welfare cannot be improved by expansion. In this sense, before attaining the full-employment equilibrium, we should adopt an active aggregate demand policy even if the velocity of economic expansion is lowered.

\section{REFERENCES}

[1] M. Otaki, "The Dynamically Extended Keynesian Cross and the Welfare-Improving Fiscal Policy," Economics Letters, Vol. 96, No. 1, 2007, pp. 23-29.

[2] M. Otaki, "A Welfare Economics Foundation for the FullEmployment Policy," Economics Letters, Vol. 102, No. 1, 2009, pp. 1-3.

[3] R. E. Lucas Jr., "Expectations and the Neutrality of Money," Journal of Economic Theory, Vol. 4, No. 2, 1972, pp. 103124.

[4] R. F. Harrod, "An Essay in Dynamic Theory," Economic Journal, Vol. 49, No. 193, 1939, pp. 14-33.

[5] J. R. Hicks, "A Contribution to the Theory of Trade Cycle," Oxford University Press, Oxford, 1950.

[6] F. Hayashi and E. C. Prescott, "The 1990s in Japan: A Lost Decade," Review of Economic Dynamics, Vol. 5, No. 1, 2002, pp. 206-235.

[7] J. M. Keynes, "The General Theory of Employment, Interest and Money," Macmillan, London, 1936.

[8] M. Otaki, "A Pure Theory of Aggregate Price Determination," Theoretical Economics Letters, Vol. 1, No, 3, 2011, pp. $122-128$. 